\title{
BMJ Open Associations between contextual and compositional characteristics of early childcare facilities with health, health behaviours and well-being among young children aged 0 to 6 years: protocol for a scoping review
}

\author{
Jennifer Hilger-Kolb (D) , ${ }^{1}$ Sven Schneider, ${ }^{1}$ Raphael Herr, ${ }^{1}$ Nina Osenbruegge, ${ }^{1}$ \\ Stephanie Hoffmann, ${ }^{2}$ Max Herke (1) ${ }^{3}$ Claudia Pischke, ${ }^{4}$ Leonie Sundmacher, ${ }^{5}$ \\ Katharina Diehl (D) ${ }^{1}$
}

To cite: Hilger-Kolb J, Schneider S, Herr R, et al. Associations between contextual and compositional characteristics of early childcare facilities with health, health behaviours and well-being among young children aged 0 to 6 years: protocol for a scoping review. BMJ Open 2020;10:e037038. doi:10.1136/ bmjopen-2020-037038

- Prepublication history and additional material for this paper are available online. To view these files, please visit the journal online (http://dx.doi. org/10.1136/bmjopen-2020037038).

Received 16 January 2020 Revised 06 August 2020 Accepted 16 August 2020

D Check for updates

(c) Author(s) (or their employer(s)) 2020. Re-use permitted under CC BY-NC. No commercial re-use. See rights and permissions. Published by BMJ.

For numbered affiliations see end of article.

Correspondence to Jennifer Hilger-Kolb; Jennifer.Hilger-Kolb@medma. uni-heidelberg.de

\section{ABSTRACT}

Introduction Early childhood is an important life stage which is crucial for determining health and health inequalities in later life. At the meso-level (institutionallevel), early childcare facilities (eg, kindergartens, preschools) are the most important agent of socialisation next to families in young children aged 06 years. In recent years, an increasing amount of studies has focused on contextual and compositional characteristics of early childcare facilities and their association with health (eg, self-rated health), health behaviour (eg, physical activity) and well-being (eg, emotional well-being) in this age group. However, as currently no overview of the available literature on this topic exists, we will conduct a scoping review including various study designs (eg, cross-sectional studies, prospective studies, qualitative studies).

Methods and analysis We will follow the Preferred Reporting Items for Systematic reviews and Meta-Analyses extension for Scoping Reviews. A systematic search of the following scientific databases will be conducted: PubMed/ Medline, Psycinfo, Sociological Abstracts, Education Resources Information Center and The Cochrane Library. During the selection process, we will follow a two-step process. First, two reviewers will independently screen titles/abstracts of all potentially eligible articles by applying a set of previously defined inclusion and exclusion criteria. After the completion of the title/abstract screening, full texts of the remaining articles will be screened following the same procedure. To determine inter-rater agreement between reviewers, we will calculate Cohen's Kappa after both steps. Key characteristics (eg, country of origin, sample size, study design) of included articles will be extracted. We will map the evidence available by providing a summary table on the key characteristics extracted and by presenting the associations using various types of illustrations. Ethics and dissemination Since no primary data will be collected for this review, ethical approval is not required. Our findings will be published in an international peer-reviewed journal and presented at national and international conferences.
Strengths and limitations of this study

This is the first scoping review focusing on the association of contextual and compositional characteristics of early childcare facilities and health (eg, self-rated health, physical health, mental health), health behaviour (eg, physical activity) and wellbeing (eg, emotional well-being) of young children.

- Population of interest are children aged 06 years who are in a life stage which is crucial for health and health inequalities in later life.

- At the meso-level (institutional-level), early childcare facilities (eg, kindergartens, preschools) are the most important agent of socialisation in this age group next to families.

- As we excluded studies conducted in non-developed countries and those in transition, our findings will represent the current state of research in developed countries only.

\section{INTRODUCTION}

Early childhood has been identified as an important life stage laying the foundation for health and well-being in later life. ${ }^{12}$ The age range between 0 and 6 years is considered ' $a$ critical window' for children's development. ${ }^{3}$ For example, health behaviours, such as physical activity and nutrition behaviour, are learnt and established at this life stage and may be maintained in the long term. ${ }^{45}$

From a socioecological perspective, health and well-being are not only determined by individual factors (eg, gender, ethnicity) but also by the environment in which the individual lives. ${ }^{6}{ }^{7} \mathrm{~A}$ common sociological analysis scheme differentiates between micro-level, meso-level and 
macro-level. While the micro-level describes individual and the macro-level societal characteristics, the mesolevel represents the institutional-level in these socioecological models. ${ }^{6}{ }^{7}$ Throughout their life, individuals are involved in different institutional contexts, such as family homes, early childcare facilities, schools, universities and the workplace. ${ }^{89}$ Therefore, in accordance with the socioecological perspective, it seems plausible that meso-level characteristics of these institutions affect health and wellbeing above and beyond the individual-level. ${ }^{9}$ For young children (aged 0-6 years), early childcare facilities are the most important agent of socialisation, next to families ${ }^{10}$ and their relevance to health and well-being of young children has long been recognised in various research disciplines (eg, social sciences, medicine and public health). As the definition of early childcare facilities varies across regions and countries, in this review we use this term for all institutions providing childcare for children in the age range between 0 and 6 years including childcare/daycare centres, family childcare homes, kindergartens, nurseries and preschools.

Previous research on this topic has especially focused on the individual-level, particularly on the association of early childcare attendance with health and wellbeing. ${ }^{11-14}$ However, in recent years, research examining the role of contextual and compositional characteristics of early childcare facilities on health, health behaviour and well-being in young children has steadily increased. While contextual characteristics describe the structural conditions of an institution (eg, duration of childcare, teacherchild interactions, equipment for outdoor activities, availability of healthy meals), compositional characteristics (eg, sex-ratio, age-ratio, immigrant-ratio) include aggregated information of the individuals attending the institution. ${ }^{15}$ For example, existing studies on contextual characteristics of early childcare facilities and associations with health, health behaviour and well-being examine spatial aspects, such as comparing early childcare facilities by location in either rural versus urban areas. ${ }^{16}$ In terms of a contextual perspective, aspects, such as activity-friendly equipment, ${ }^{17-20}$ space for playing ${ }^{21}$ and playground surface ${ }^{202}$ at the childcare-level were analysed in relation to children's physical activity behaviour. Regarding compositional aspects at the meso-level, existing studies focused, for example, on associations between socioeconomic position of the childcare facilities and physical activity behaviour, ${ }^{23-25}$ nutrition behaviour ${ }^{24}$ or mental health of the young children. ${ }^{26}$

It is well known from previous research that health inequalities already exist among young children. For instance, children whose parents have a lower socioeconomic position are more likely to be physically inactive, ${ }^{27}$ consume unhealthy meals and snacks ${ }^{27-29}$ and to show worse health outcomes ${ }^{30-32}$ than those coming from families with a higher socioeconomic position. However, it still remains unclear whether compositional and contextual factors mediate or moderate emerging health inequalities. If this is the case, changing context and composition at the early childcare-level could be one strategy to reduce childhood health inequalities.

Currently no comprehensive review that provides an overview of the literature available regarding associations between contextual and/or compositional characteristics at the childcare-level with health, well-being and health behaviours of young children exists. Such a review would be helpful to identify existing knowledge gaps and to guide future research. While classical systematic reviews are usually conducted to answer clearly defined research questions to inform the development of evidence-based guidelines, scoping reviews typically deal with broader research questions to examine the type and nature of evidence currently available on a given research topic. ${ }^{33} 34$ Hence, we will conduct a scoping review to answer the following questions:

1. Which compositional and contextual characteristics of early childcare facilities are associated with health, health behaviours and well-being in young children aged 06 years?

2. In which way is the association between socioeconomic position and health mediated or moderated by compositional and contextual characteristics of the childcare context?

\section{METHODS AND ANALYSIS}

This review will be based on the Preferred Reporting Items for Systematic reviews and Meta-Analyses extension for Scoping Reviews (PRISMA-ScR) ${ }^{34}$ As this work is a review of published work, ethical approval is not required.

\section{Eligibility criteria}

Studies will be eligible for inclusion, if they meet the following criteria:

In line with the characteristics of a scoping review, not only quantitative study designs (eg, cross-sectional studies, prospective studies, cohort studies, casecontrol studies, baseline data of intervention studies) but also qualitative ones will be eligible for inclusion. The population of interest are children aged 0to 6 years who attend an early childcare facility. Factors of interest will be various compositional (eg, gender, age, migration background, socioeconomic position) and/or contextual characteristics (eg, type of childcare, staff characteristics, norms, opportunities for physical activities, resources for healthy nutrition) of childcare facilities. Due to our aim to provide a broad overview on the literature available, we decided to follow the approach of Priest $e t a l^{35}$ who regarded health and well-being from a 'holistic' perspective, including various measures of negative, as well as positive health outcomes, across physical, mental and behavioural areas. Main outcomes will include health (eg, self-rated health status, respiratory tract infections, gastrointestinal illnesses), health behaviours (eg, nutrition, physical activity) and 
additional health-related outcomes (eg, emotional and physical well-being, quality of life). The only condition that the outcomes will have to fulfil is that they have to be assessed at the child-level. However, no further restrictions on assessment methods (eg, questionnaire, interview, blood samples and urinary samples) and reporting formats (eg, self-reported, parent-reported, clinical examination) will be made. Only articles of studies conducted in developed countries (according to the country classification of the United Nations) ${ }^{36}$ will be considered because various socioecological differences exist between developed countries, countries in transition and developing countries. Articles published in English or German between 1 January 2000 and the date of final database screen will be considered for inclusion. A detailed overview of all inclusion and exclusion criteria is provided in table 1 .

\section{Information sources and search strategy}

The following scientific literature databases will be searched for potentially eligible articles: PubMed/ Medline, PsycInfo, Sociological Abstracts, ERIC (Education Resources Information Center) and The Cochrane Library. Although we will not include reviews, The Cochrane Library will be searched for reviews which examined studies probably fitting the inclusion criteria, as we will screen the reference lists of these reviews for further relevant articles. The search strategy was first developed for Pubmed/Medline and afterwards adapted to the other scientific databases. For the search in Pubmed/Medline keywords were selected from the Medical Subject Headings (MeSH) Thesaurus and complemented with additional relevant free-text terms. For example, we included search terms such as: preschool*[Title/Abstract], kindergarten*[Title/Abstract], context[Title/Abstract], meso-level, caregivers(MeSH), Pre-School Teacher[Title/Abstract], child-teacher relationship[Title/Abstract], classroom size[Title/Abstract], quality of care[Title/Abstract], playground[Title/ Abstract], health $[\mathrm{MeSH}]$, quality of life $[\mathrm{MeSH}]$, dietary intake[Title/Abstract], meal times[Title/Abstract], physical activity[Title/Abstract], wellbeing[Title/Abstract]. The full search strategy applied to Pubmed/Medline can be found in the online supplementary additional file 1 . Search strategies for all other databases will be available from the corresponding author on request. Database searches will be conducted by an experienced medical librarian. Search results will be downloaded into the reference management tool EndNote V.X8 (Thomson Reuters), and all duplicates will be removed using this tool. Afterwards, the remaining articles will be uploaded to Rayyan, ${ }^{37}$ an internet-based software for managing the study selection process.

\section{Study selection process}

The selection process will consist of two steps of screening: in a first step, title and abstract will be reviewed; in a second step, a full-text review will be conducted for those papers included during the first step. Both screening steps will be conducted independently by two reviewers (JH-K and KD) based on a set of previously defined inclusion and exclusion criteria (table 1 ).

To determine inter-rater agreement between reviewers, we will calculate Cohen's Kappa after both phases. Disagreements will be resolved via discussion between both reviewers. In case, agreement between both reviewers cannot not be achieved, a third author (RH) who is familiar with the scoping review will make the final decision.

Relevant studies will be included if they meet the abovementioned eligibility criteria. The applicability of these criteria has been pretested in an exemplary test selection by three of the authors ( $\mathrm{n}=100$; by JH-K, RH and KD). We will provide an overview of number of studies included in each step of the study selection process using the PRISMA flow diagram.

\section{Data extraction process}

Two authors will extract the data from the articles of all studies included in the scoping review. This procedure will be based on a standardised data extraction form. To ensure a high quality of data extracted, we plan a double extraction of $5 \% 10 \%$ of all articles included.

The following data will be extracted: author names, year published, year of study execution, country of origin, study type, number of participants, basic characteristics of participants, compositional and contextual characteristics of early childcare facilities and outcome measures. Although quality assessment of studies included is not mandatory for scoping reviews, we will extract some general quality indicators (eg, sample size, selection of participants, occurrence of a selection bias and limitations stated by the authors). We will also identify multiple articles of the same study during the data extraction process. However, in case that these articles will report on different information of interest such as different compositional or contextual characteristics or different outcomes, we will label these articles as multiple articles of the same study but include all articles in the data mapping process.

\section{Analysis and presentation of results}

In a first step, we will provide a summary table on the main characteristics of articles extracted including the following: years of publication, country of origin, sample size and study designs. In a second step, we plan to map the evidence found on associations between compositional/contextual factors at early childcare centres and health, health behaviours and well-being. In this mapping process, we will take the outcome measures as a starting point. Depending on the number of studies that will be available for each outcome, we will classify the outcomes into different main categories (eg, physical health/development, mental health/development, physical activity, nutrition behaviour). The final outcome categories will be determined after data 
Table 1 Overview of inclusion and exclusion criteria applied during the selection process

\begin{tabular}{|c|c|c|}
\hline & Included & Excluded \\
\hline Study designs & $\begin{array}{l}\text { Cross-sectional studies } \\
\text { Cohort studies } \\
\text { Prospective studies } \\
\text { Case-control studies } \\
\text { Qualitative studies } \\
\text { Intervention studies (only baseline data) }\end{array}$ & $\begin{array}{l}\text { Case studies } \\
\text { Cell studies } \\
\text { Reviews } \\
\text { Author replies/comments } \\
\text { Animal studies }\end{array}$ \\
\hline Populations & $\begin{array}{l}\text { Children aged 0-6 years attending an early childcare } \\
\text { facility }\end{array}$ & $\begin{array}{l}\text { Children aged } 06 \text { years not attending an early childcare } \\
\text { facility } \\
\text { Patient samples (children with specific conditions/ } \\
\text { diseases) } \\
\text { Older age groups (eg, school children, adolescents, } \\
\text { adults, elderly people) }\end{array}$ \\
\hline \multirow[t]{2}{*}{ Factors of interest } & $\begin{array}{l}\text { Compositional characteristics at the early childcare-level: } \\
\text { Gender } \\
\text { Age } \\
\text { Immigrant background } \\
\text { Language skills } \\
\text { Socioeconomic position } \\
\text { Parental commitment }\end{array}$ & $\begin{array}{l}\text { Compositional characteristics outside the early childcare- } \\
\text { level: } \\
\text { At the family level } \\
\text { In the home environment } \\
\text { In other institutions (eg, in schools) }\end{array}$ \\
\hline & $\begin{array}{l}\text { Contextual characteristics at the early childcare level: } \\
\text { Location of childcare facility } \\
\text { Type of childcare facility (private, public) } \\
\text { Childcare facility size } \\
\text { Group size } \\
\text { Duration of childcare (full-time, half-time) } \\
\text { Teacher/child ratio } \\
\text { Staff characteristics (eg, number, age, sex, migration } \\
\text { background, qualification) } \\
\text { Toys/playing equipment } \\
\text { Financial resources } \\
\text { Opportunities for PA (eg, sport rooms, outdoor area, } \\
\text { playground) } \\
\text { Equipment for PA } \\
\text { Integration of PA in daily routines } \\
\text { Projects that promote PA } \\
\text { Resources for healthy eating } \\
\text { Cooking facilities } \\
\text { Lunch/other meals offered } \\
\text { Food quality } \\
\text { Free access to water/food } \\
\text { Nutrition rules (eg, lunch box content) } \\
\text { Projects that promote healthy eating }\end{array}$ & $\begin{array}{l}\text { Contextual characteristics outside the early childcare-level: } \\
\text { At the family level } \\
\text { In the home environment } \\
\text { In other institutions (eg, in schools) }\end{array}$ \\
\hline Outcomes & $\begin{array}{l}\text { Health outcomes (eg, self-rated health, physical health, } \\
\text { mental health) } \\
\text { Health behaviour (eg, nutrition, PA sedentary behaviour, } \\
\text { media consumption, passive smoke exposure) } \\
\text { Other health-related outcomes (eg, obesity, well-being, } \\
\text { quality of life) }\end{array}$ & \\
\hline Regions/countries & - Developed countries & $\begin{array}{l}\text { Developing countries } \\
\text { Countries in transition }\end{array}$ \\
\hline Languages & $\begin{array}{l}\text { English } \\
\text { German }\end{array}$ & All other languages \\
\hline
\end{tabular}

PA, physical activity

extraction will be completed. Based on the respective outcome category,we will provide a graphical illustration on the associations found (none, positive, negative) with the contextual/compositional characteristics at the early childcare facilities. As no statistical associations can be drawn from qualitative studies, we will not include them in the graphical illustrations. However, we will report their findings in the text of the results section and will contrast their findings with those of the quantitative ones. Furthermore, the mapped evidence will be accompanied by a clear descriptive summary in the text part of the results section.

In conclusion, we will conduct the first scoping review that will summarise existing evidence on associations of contextual/compositional characteristics of early childcare facilities and health, health behaviour and 
well-being of young children. A comprehensive overview on this topic will be helpful to identify existing knowledge gaps and to guide future research efforts. However, as we will not include articles from studies that have been conducted in developing countries or countries in transition, findings will represent the current state of research in developed countries only. Thus, future research efforts should summarise the available literature on this topic in less developed countries to extend our work and end up with a worldwide picture.

\section{Patient and public involvement}

No patients involved.

\section{ETHICS AND DISSEMINATION}

Ethical approval is not required because no primary data will be collected for this scoping review and all studies will be identified via literature searches in scientific databases. Our findings will be published in an international peer-review journal and presented at national and international conferences.

\section{Author affiliations}

${ }^{1}$ Mannheim Institute of Public Health, Social and Preventive Medicine, Medical Faculty Mannheim, Heidelberg University, Mannheim, Germany

${ }^{2}$ Department of Public Health, Faculty for Social Work, Health, and Music, Brandenburg University of Technology Cottbus-Senftenberg, Senftenberg, Germany ${ }^{3}$ Institute of Medical Sociology, Medical Faculty, Martin-Luther-University HalleWittenberg, Halle (Saale), Germany

${ }^{4}$ Institute of Medical Sociology, Centre for Health and Society, Medical Faculty, Heinrich-Heine-University Duesseldorf, Duesseldorf, Germany

${ }^{5}$ Department of Health Economics, Department of Health Science, Technical University of Munich, Munich, Germany

Acknowledgements The authors thank Maurizio Grilli from the library of the Medical Faculty Mannheim for his valuable assistance in adapting the search strategy to Sociological Abstracts and ERIC and for conducting the electronic databases searches for all databases considered.

Contributors $\mathrm{JH}-\mathrm{K}$ and KD drafted the manuscript. JH-K, SS, RH and KD contributed to the development of the selection criteria. JH-K, SS, RH, NO and KD contributed to the development of the search strategy. SS, RH, NO, SH, MH, LS and $\mathrm{CP}$ critically revised the draft manuscript for important intellectual content. All authors read and approved the final version of the manuscript.

Funding This work was supported by the German Research Foundation (DFG) grant number FOR2723 (project number 384210238). The individual grant number for the subproject is: SCHN727/9-1. The funding organisation had no role in the design, analysis and interpretation of the data, in writing the manuscript or to submit the manuscript for publication.

Disclaimer Since no primary data will be collected for this scoping review, ethical approval is not required.

Competing interests None declared.

Patient consent for publication Not required.

Provenance and peer review Not commissioned; externally peer reviewed.

Open access This is an open access article distributed in accordance with the Creative Commons Attribution Non Commercial (CC BY-NC 4.0) license, which permits others to distribute, remix, adapt, build upon this work non-commercially, and license their derivative works on different terms, provided the original work is properly cited, appropriate credit is given, any changes made indicated, and the use is non-commercial. See: http://creativecommons.org/licenses/by-nc/4.0/.

\section{ORCID iDs}

Jennifer Hilger-Kolb http://orcid.org/0000-0003-0347-1900
Max Herke http://orcid.org/0000-0001-6425-4366

Katharina Diehl http://orcid.org/0000-0002-5408-652X

\section{REFERENCES}

1 Ben-Shlomo Y, Kuh D. A life course approach to chronic disease epidemiology: conceptual models, empirical challenges and interdisciplinary perspectives. Int J Epidemiol 2002;31:285-93.

2 Braveman P, Barclay C. Health disparities beginning in childhood: a life-course perspective. Pediatrics 2009;124 Suppl 3:S163-75.

3 Muennig P, Schweinhart L, Montie J, et al. Effects of a prekindergarten educational intervention on adult health: 37-year follow-up results of a randomized controlled trial. Am J Public Health 2009;99:1431-7.

4 Bundeszentrale für gesundheitliche Aufklärung. Gesundheitsförderung Im kindergarten. Köln: Bundeszentrale für gesundheitliche Aufklärung (BZgA), 2001.

5 Strauss A, Herbert B, Mitschek C, et al. [TigerKids. Successful health promotion in preschool settings]. Bundesgesundheitsblatt Gesundheitsforschung Gesundheitsschutz 2011;54:322-9.

6 Lakshman R, Mazarello Paes V, Hesketh K, et al. Protocol for systematic reviews of determinants/correlates of obesity-related dietary and physical activity behaviors in young children (preschool 0 to 6 years): evidence mapping and syntheses. Syst Rev 2013;2:28.

7 McLeroy KR, Bibeau D, Steckler A, et al. An ecological perspective on health promotion programs. Health Educ Q 1988;15:351-77.

8 Blum RW, Bastos FIPM, Kabiru CW, et al. Adolescent health in the 21st century. Lancet 2012;379:1567-8.

9 Richter M, Dragano N, Micro DN. Micro, macro, but what about meso? the institutional context of health inequalities. Int J Public Health 2018;63:163-4.

10 von Suchodoletz A, Fäsche A, Gunzenhauser C, et al. A typical morning in preschool: observations of teacher-child interactions in German preschools. Early Child Res Q 2014;29:509-19.

11 D'Onise K, McDermott RA, Lynch JW. Does attendance at preschool affect adult health? A systematic review. Public Health 2010;124:500-11.

12 Caniato RN, Alvarenga ME, Stich HL, et al. Kindergarten attendance may reduce developmental impairments in children: results from the Bavarian pre-school morbidity survey. Scand J Public Health 2010;38:580-6.

13 Sabol TJ, Hoyt LT. The long arm of childhood: preschool associations with adolescent health. Dev Psychol 2017;53:752-63.

14 Cooper H, Allen AB, Patall EA, et al. Effects of full-day kindergarten on academic achievement and social development. Rev Educ Res 2010;80:34-70.

15 Duncan C, Jones K, Moon G. Context, composition and heterogeneity: using multilevel models in health research. Soc Sci Med 1998;46:97-117.

16 Stich HL, Caniato RN, Krämer A, et al. Influence of kindergarten on numbers of multiple developmental delays in preschoolers: an analysis over 14 years. Int J Public Health 2017;62:613-21.

17 Bower JK, Hales DP, Tate DF, et al. The childcare environment and children's physical activity. Am J Prev Med 2008;34:23-9.

18 Gubbels JS, Van Kann DHH, Jansen MWJ. Play equipment, physical activity opportunities, and children's activity levels at childcare. $J$ Environ Public Health 2012;2012:1-8.

19 Hannon JC, Brown BB. Increasing preschoolers' physical activity intensities: an activity-friendly preschool playground intervention. Prev Med 2008;46:532-6.

20 Cardon G, Van Cauwenberghe E, Labarque V, et al. The contribution of preschool playground factors in explaining children's physical activity during recess. Int J Behav Nutr Phys Act 2008;5:11.

21 Olesen LG, Kristensen PL, Korsholm L, et al. Physical activity in children attending preschools. Pediatrics 2013;132:e1310-8.

22 Cosco NG, Moore RC, Islam MZ. Behavior mapping: a method for linking preschool physical activity and outdoor design. Med Sci Sports Exerc 2010;42:513-9.

23 Arhab A, Messerli-Bürgy N, Kakebeeke TH, et al. Childcare correlates of physical activity, sedentary behavior, and adiposity in preschool children: a cross-sectional analysis of the SPLASHY study. J Environ Public Health 2018;2018:1-12.

24 Jones J, Wyse R, Wiggers J, et al. Dietary intake and physical activity levels of children attending Australian childcare services. Nutr Diet 2017;74:446-53.

25 Eichinger M, Schneider S, De Bock F. Subjectively and objectively assessed social and physical environmental correlates of preschoolers' accelerometer-based physical activity. Int J Behav Nutr Phys Act 2017;14:153. 
26 Boyce WT, Obradović J, Bush NR, et al. Social stratification, classroom climate, and the behavioral adaptation of kindergarten children. Proc Natl Acad Sci U S A 2012;109 Suppl 2:17168-73.

27 D'Souza NJ, Kuswara K, Zheng M, et al. A systematic review of lifestyle patterns and their association with adiposity in children aged 5-12 years. Obes Rev 2020;21:e13029.

28 Avery A, Anderson C, McCullough F. Associations between children's diet quality and watching television during meal or snack consumption: a systematic review. Matern Child Nutr 2017;13. doi:10.1111/mcn.12428. [Epub ahead of print: $17 \mathrm{Feb} 2017$ ].

29 Pinket A-S, De Craemer M, Huybrechts I, et al. Diet quality in European pre-schoolers: evaluation based on diet quality indices and association with gender, socio-economic status and overweight, the ToyBox-study. Public Health Nutr 2016;19:2441-50.

30 Appleton AA, Holdsworth EA, Kubzansky LD. A systematic review of the interplay between social determinants and environmental exposures for early-life outcomes. Curr Environ Health Rep 2016;3:287-301.
31 Liu RS, Aiello AE, Mensah FK, et al. Socioeconomic status in childhood and $C$ reactive protein in adulthood: a systematic review and meta-analysis. J Epidemiol Community Health 2017;71:817-26.

32 Pillas D, Marmot M, Naicker K, et al. Social inequalities in early childhood health and development: a European-wide systematic review. Pediatr Res 2014;76:418-24.

33 Munn Z, Peters MDJ, Stern C, et al. Systematic review or scoping review? guidance for authors when choosing between a systematic or scoping review approach. BMC Med Res Methodol 2018;18:143.

34 Tricco AC, Lillie E, Zarin W, et al. PRISMA extension for scoping reviews (PRISMA-ScR): checklist and explanation. Ann Intern Med 2018;169:467-73.

35 Priest N, Paradies Y, Trenerry B, et al. A systematic review of studies examining the relationship between reported racism and health and wellbeing for children and young people. Soc Sci Med 2013;95:115-27.

36 Nations U. World economic situation and prospects 2019, 2019.

37 Ouzzani M, Hammady H, Fedorowicz Z, et al. Rayyan-a web and mobile APP for systematic reviews. Syst Rev 2016;5:210. 